cold damp of the ground, should he at any time find it necessary to walk over such ground. The thin summer boots which are worn here will indeed be found preferable to shoes, especially as a protection against the stings of musquitoes, to which every day and everywhere there will be more or less exposure. On this topic 1 need only ardd, that the cornmon hat of the West Indies is the Panama hat. But it is uncomfortably heavy. A broad-brimmed, and light white beaver, or wool hat, will be found far more agreeable. The roarls in the country, and the streets at West End, are covered with marl, which gives a painful brilliancy to the light. Not only, therefore, will a broad brim to the hat be found a great convenience, as a protection of the eyes, but I would advise every one who shall go there to carry with him spectacles with colored glass, and a light umbrella to be used as a parasol. 'This parasol will be far more frequently needed, than a larger and heavier umbrella for protection against the rain. I give you this detail, because the particulars comprehended in it were daily forced upon my attention, by the observation and experience of the last winter. $\Lambda$ cold may be taken in an hour, as well as in a day; and a large proportion of the colds, from which have resulted the diseases which have terminated in death, have been from short exposures, and might have been avoided by a proper attention to clothing with respect to the exigency of the time.

['To be continued.]

\title{
A SINGULAR CASE.
}

[Communicnted for tho Boston Medical and Surgical Journal.]

Mns. F. was confined, with her first child, in March, 1835. Nothing uncommon occurred during labor. After the delivery of the sccundines, hæmorrhage commenced. Dr. K., her accoucheur, employed such remedies as were at hand, and among others, the tampon. The hxmorrhage subsided, and Dr. K., being called to another patient, left her, with directions to keep her cool and quiet. The doctor returned in a few hours; found her in considerable pain, but no hxonorrhage ; directed an anodyne, elix. paregoric, and requested Mrs. S., the mother of the patient, to remove the cloths in the norning. The following day the Dr. called, and made inquiry of Mrs. S. whether she had done as directed. She replied, "I removed all I could find." She had at this time considerable pain, for which an anodyne was prescribed. In a few days from the time of her accouchment the lochia became rather profuse and quite foetid. She continued in this condition four or five weeks, with the lochia increasing in quantity and fotor. She was unable to leave her bed, and it was thought best to have counsel. Dr. W., an aged physician of respectability and much experience, met Dr. K. Dr. W. made inquiries in relation to ber labor and condition up to the time, and inquired in regard to the uterus, whether all was right. Dr. $\mathrm{K}$. replied in the affirmative. Dr. W. did not make any examination per vaginan-thought it not necessary, from the representations made lim by $\operatorname{Dr}$. K. Some little change in the constitutional remedies was the 


\section{A Singular Case.}

result of the consultation. She improved somewhat in strength under treatinent, and after a short time was able to leave her bed, but could not sit down, and could walk only when the perineum was sustained by the band, as the weight and pressure of something hurt her very considerably. She contrived a suspensory bandage, which added much to her comfort, although the continual discharge made it uncomfortable to wear. At this time the discharge from the vagina was profuse and intolerably foctid.

At the expiration of some four months, her sufferings being very severe, she concluded to have still further advice. Dr. McG. was called, who mot Dr. K. An examination was had. They found something low in the vagina, around which, Dr. McG. remarked, he could pass his finger; that whatever it should prove to be, it was tender to the touch, or that an examination, on account of the increased sensibility of the parts, was painful. 'They did not, however, arrive at any definite conclusion as regirded the pathology of her case, but concluded to have another consultation the next week, which, however, did not take place. $\Lambda$ bout this time she commenced using injections, with the view of keeping the parts clean, and thus obviating foetor.

She passed along without any favorable change until another four months had expired, alike oflensive to herself and to all about her, suffering not only from the stench, but from pain and the excoriating effects of the discharge, bandage, \&c., until her sufferings became absolutely insupportable. She concluded to make one more effort to obtain relief, and sent for Dr. H., who visited her, inade an examination, called her difficulty a retroversion of the uterus, directed injections of a solution of creosote, and left her. 'The directions of Di. H. gave her no relief, and she gave up all idea of again being restored to health. From time to time, when she had felt more than usual the "falling down," as she called it, she had, as well as she could, endeavored to see what it was that troubled her so much, and had remarked, through her mother, to Dr. K., that it looked like coarse threads passing over each other. The doctor said it might be the vessels of the womb enlarged.

Thus she suffered from week to week, and from month to month, without any alleviation, until about the middle of the month of April, 1836. In one of her examinations at this time, she found the appearance and color of the thing had changed, and become quite dark. She made up her mind fully that the womb was mortified, and thought, as a matter of course, that she must dic. She called some of her female friends, stated to them her fears, and asked their advice. They decided upon an autopsical examination. They found something of a dark color low in the vagina, and from it hung some shreds, looking like decayed animal matter. These they carefully detached, and on a minute inspection concluded they were composed of materials with which they were better acquainted than they were with the tissues of the human system, even linen threads. Dr. K. was innnediately sent for. He came, and removed from the vagina the one balf of a coarse linen pillow case, which he had thirteen months before placed there in the shape of a tampon. The offensive discharge immediately ceased, her health and 
strength returned rapidly, and in a short time she was well, and, I may now add, lias borne twins.

These lacts (for facts they are) require at my hands no comment. If the circumstances here related will serve to impress more strongly upon the mind of the young practitioner the importance of removing the tampon when it may have been judiciously applied, and of care in making examinations per vaginam, the reporter of this case will feel himself abundantly rewarded.

Should the tampon ever be applied after delivery at the full period of utero-gestation?

$$
\text { Cayuga Co., N. Y., June, } 1837 .
$$

ElsLio'T.

\section{CASE OF DRY gANGRENE SUCCESSFULI,Y TREATED.}

\section{To the Editor of the Boston Medical and Surgical Journal.}

Sin,-I have drawn up a sketch of a case of gangrena necrosis of Good, which, if you think worthy an insertion in your Journal, I shall not think my labor is spent for naught.

Mrs. G., an Irish woman, was delivered of a female infant at the Lyingin Hospital, Boston, according to her statement, Nov. 26, 18:36. The child did well and evinced every mark of health up to the 14 th or 15 th of Feb., 18:37, when at night the mother noticed the following symptoms: vomiting, restlessness, jactitation, thirst, heat of the skin, \&c. These symptoms continued, and the next day two or more livid spots were noticed on the nates, nearly the size of the adult finger nail. The skin by this time began to shrink, became livid, dry and dusky. The eyes presented a peculiar appearance, being partly rolled up in their sockets. They had the appearance of great distress of body and nind, and seemed to sparkle with brightness; projecting, as it were, from their orbits, it seemed as if they would fly from the head of the little sufferer.

These symptoms continued, with little or no mitigation, but with an addition of many others, till Feb. 28th, when I was called to see it. I found it strugnling in agony. All the symptoms above named were present, and others, as screaming, clonic spasms and sloughing of the nates. The pulse were quick, so much so that it was not easy to count them. The skin was shrivelled, livid, very dry and inelastic. There was inuch emaciation, the patient appearing to be little else than "skin and bone." More than one third of the Hesh of the nates had been thrown off, leaving a surface very tender to the touch, red and bleeding. On the right natis, was a piece of deadened flesh, as large, upon the exterior surface, as the three principal fingers of the adult hand. It was black, dry, and hard as wood. The surrounding parts were emaciated and withered, evidently showing that the animal oil, flesh and fluids, were absorbed; "mummia instar pars affecta."-Prof. Frank. Its appetite was morbidly keen; it would take almost anything into the stomach, but would immediately reject it. This had been a uniform symptom, according to the statement of the mother.

Upon a close examination, I thought the natural indication was a 